\title{
O SENTIR EM EXCESSO: O SENSACIONISMO EM ÁLVARO DE CAMPOS E MÁRIO DE SÁ-CARNEIRO
}

Karine Costa Miranda ${ }^{1}$

Geisiane Dias Queiroz ${ }^{2}$

Maria Elvira Brito Campos ${ }^{3}$

RESUMO: Este trabalho propõe investigar, dentre as manifestações poéticas de um determinado período da literatura portuguesa, a estética sensacionista. O momento literário eleito é o que caracteriza a obra de alguns escritores da geração de Orpheu, também conhecida como primeira geração modernista. Como representantes do movimento modernista em Portugal, entre os séculos XIX e XX, Fernando Pessoa e Mário de Sá-Carneiro difundiram nessa poética "o sentir em excesso". A partir da análise dos poemas "Afinal, a melhor maneira de viajar é sentir" e "Rodopio", esse trabalho objetiva debruçar-se sobre essa perspectiva sensacionista.

PALAVRAS-CHAVE: Sensacionismo; Fernando Pessoa; Mário de Sá-Carneiro.

\section{FEELING IN EXCESS: THE SENSATIONISM IN ÁLVARO DE CAMPOS AND MÁRIO DE SÁ-CARNEIRO}

ABSTRACT: This study aims to investigate, among the poetic expressions of a certain period of Portuguese literature, the aesthetic sensacionista. The chosen literary period comprising generating Orpheu, also known as the first modernist generation. As representatives of the modernist movement in Portugal, between the 19th and 20th centuries, Fernando Pessoa and Mário de SáCarneiro spread this feeling of poetic excess. From the analysis of the poems "Afinal, a melhor maneira de viajar é sentir" and "Rodopio", this study aims to look into the sensationist perspective. KEYWORDS: Sensationism; Fernando Pessoa; Mário de Sá-Carneiro.

\footnotetext{
${ }^{1}$ Graduada em Letras Português /Espanhol (UFMA). Mestranda em Letras - Estudos Literários (UFPI). Bolsista CAPES. E-mail: karine_letters@yahoo.com.br

${ }^{2}$ Graduada em Letras Português (UFPI). Mestranda em Letras - Estudos Literários (UFPI). Bolsista CAPES. E-mail: geisydias@gmail.com

3 Professora Doutora pela USP, Pós-Doutoranda em Literatura pela Universidade de Coimbra, Bolsista Sênior pela CAPES. Professora de Literatura Portuguesa na Universidade Federal do Piauí. E-mail: mebcampos@hotmail.com
} 
A sensação é nitidamente do exterior mas, ao mesmo tempo, esse sentimento (ou sensação) do exterior, do físico, é sempre acompanhada por uma obscura consciência do exterior, do psíquico (PESSOA, 1976, p. 426).

O Sensacionismo começou com a amizade entre Fernando Pessoa e Mário de Sá-Carneiro. Provavelmente é difícil separar a parte que cada um deles teve na origem do movimento, e de certo completamente inútil determiná-la. O fato é que eles ergueram os começos entre si (PESSOA, 1976, p. 450).

Como em quase todos os países da Europa, o início do século XX em Portugal foi marcado por uma aguda crise econômica, política e social, derivada da dissolução de valores decorrentes da Primeira Guerra Mundial, assim como pela implantação da República Portuguesa. Alguns artistas reagiram a essa mudança de sistema político com ceticismo, expresso no sarcasmo com que difundiam suas ideias, ou mesmo, contraditoriamente aos mais exaltados, no externar excessivo das suas sensações: daí, o sensacionismo.

O Modernismo encerrou um humanismo produtivo por meio da incitação à plenitude individual, e despontou, intuitivamente, em uma visão do mundo como coisa absurda e sem suporte. Como apontado por Fidelino de Figueiredo, em História literária de Portugal, "o moderno é aquilo que é novo e que por isso mesmo se distingue de uma tradição esgotada, em geral, ao instaurar outra espécie de tradição" (FIGUEIREDO, 1966, p. 103), tradição aquela que é rompida por meio do culto exagerado do "eu", provocando uma cisão entre o homem e o mundo.

Como afirma Carlos Reis em $O$ conbecimento da literatura, em Portugal, o aparecimento e a maturação do Modernismo relacionam-se com a "relevância cultural assumida por algumas revistas e naturalmente pelos autores que nelas colaboraram" (REIS, 1999, p. 455-456). Desse modo, a introdução do Modernismo em Portugal foi constituída pela publicação do primeiro número da revista Orpheu, em março de 1915.

Nessa perspectiva, nota-se a presença de concepções literárias já conhecidas: a arte vista como "um segredo ou tormento" de alguns temperamentos para os quais Orpheu é um "exílio" e um "ideal oculto", uma forma bem particular de o artista sentir e conhecer a si próprio - o que lhes permitia fazer diversas revelações.

Orpheu incluiu entre seus colaboradores Fernando Pessoa, Mário de Sá-Carneiro, 
Almada-Negreiros, entre outros autores ${ }^{4}$. Muitos desses trabalhos estavam afinados com as ideias estéticas mais revolucionárias da Europa de então - as Vanguardas - e provocaram reações escandalizadas da imprensa e do público. Deve-se destacar que essa intenção de "escandalizar a burguesia" era um dos propósitos dos colaboradores da revista. A geração de Orpheu surgiu como ponto de arranque em mais de uma direção - começo de uma nova época, liquidação de certas formas de pensar e de sentir. De acordo com Carlos Reis, a multiplicação de movimentos é "evidência de grande efervescência cultural e, simultaneamente, de uma certa crise ideológica" (REIS, 1999, 457). O Modernismo apresentou a confluência de múltiplos movimentos: o Ultraísmo, o Imagismo, o Construtivismo, o Expressionismo, o Cubismo, e levando em conta o panorama português, "o Sensacionismo, o Interseccionismo, o incipiente Paúlismo, o Neo-Paganismo e o Futurismo" (REIS, 1999, p. 458).

A literatura não era mais só expressão do indivíduo, mas a linguagem que se constituía inesperada, a partir de um vazio, de um "não-eu”. Logo, Orphen conseguiu, de modo eclético, questionar o convencionalismo da literatura portuguesa da época e apresentar as correntes estéticas mais renovadoras ao público.

Ainda que uma das propostas da revista Orphen fosse a ruptura com o passado, foi o mesmo passado recente da guerra de 1914 que motivou as vanguardas, pois colocou o homem frente ao espelho da alma. Com efeito, a geração de Orpheu, por meio de atitudes irreverentes e pela assumida consciência de uma necessidade de revolução cultural no país, disseminou na cultura portuguesa o combate ao imobilismo e ao atraso cultural. A criação de uma nova poesia, de uma nova prosa e de uma nova crítica se configuraram na geração orfista. Nesse contexto, pode-se destacar Fernando Pessoa e Mário de Sá-Carneiro, a fim de melhor exemplificar a estética do Sensacionismo e os aspectos que a permeiam.

Fernando Pessoa, nascido em Lisboa em 13 de junho 1888, foi um dos poetas da geração Orpheu e, junto com Mário de Sá-Carneiro e Raul Leal, fundou a revista que teve seu primeiro número em 1915. Um dos casos mais complexos da literatura portuguesa, Fernando Pessoa foi criador de diversos personagens poéticos, os chamados heterônimos. Os mais conhecidos são Alberto Caeiro, Ricardo Reis e Álvaro de Campos.

Fernando Pessoa criou a biografia de cada um dos seus heterônimos - com direito

\footnotetext{
4 Os colaboradores da revista foram Fernando Pessoa, Mário de Sá-Carneiro e Raul Leal, mais Santa-Rita Pintor, Luís de Montalvor, Almada-Negreiros, Rui Coelho, Tomás de Almeida, Alfredo Guisado, Amando Cortes-Rodrigues e o brasileiro Ronald de Carvalho.
} 
a mapa astral e assinatura. Álvaro de Campos nasceu em Tavira, em 15 de outubro de 1890, portanto apenas dois anos mais novo que seu criador Pessoa. Cursou engenharia mecânica e naval na Escócia. Viveu em Lisboa e escrevia razoavelmente em português.

Nascido em Lisboa em 19 de maio de 1890, Mário de Sá-Carneiro pertenceu à geração do grupo Orpheu. Sá-Carneiro escreveu contos (Princípio, 1912; Céu em fogo, 1915), narrativa (A confissão de Lúcio, 1914), poesia (Dispersão, 1914, a que se juntaram os poemas de Indícios de Oiro, formando suas Poesias completas, publicadas em 1946) e teatro (Amizade, 1912). Em 1958 e 1959, foram publicadas as Cartas a Fernando Pessoa, em dois volumes, de extrema importância para a compreensão da trajetória estética.

Sá-Carneiro levou ao extremo algumas tendências da poesia simbolista, mesclandoas com elementos mais modernos. Em seus textos, combina a exploração da musicalidade inovadora e as frases nominais. Seu principal tema foi a reflexão, muitas vezes desesperada, sobre a incapacidade de estruturar uma personalidade capaz de lidar com a mesquinhez do cotidiano.

Massaud Moisés (1980) em seus estudos acerca da Literatura Portuguesa, apresenta Mário de Sá-Carneiro como "poeta e tão-somente poeta, inclusive nos contos, no teatro e na narrativa" (MOISÉS, 1980, p. 305). Moisés caracteriza Sá-Carneiro como ocupante de um lugar à parte na evolução histórica da Literatura Portuguesa, devido à sua marca de individualidade e originalidade. Caracteriza-o, ainda, como "dono duma insólita hipersensibilidade, aguçada ao extremo do delírio e da loucura [...] o poeta ganha muito cedo a angustiante sensação de ser estranho à vida, e de esta ser igual e totalmente estranha" (MOISÉS, 1980, p. 306). Possuidor de um estilo próprio e intenso, em seus poemas tratou do caos de sensações e sofrimentos.

Fernando Paixão (2005) considera que "Sá-Carneiro é efetivamente um poeta das sensações. Voltado para a construção de um eu-lírico que oscila entre um plano idealizado [...] seus versos procuram recriar, em nível simbólico, uma 'vibração emocional' própria e singular" (PAIXÃO, 2005, p. 21). Sobre o estilo do poeta:

Sá-Carneiro é, sem dúvida, um desses artistas cientes do estilo. Sua poesia insere-se num limiar entre a expressão dos desvarios do sofrimento - a dor de alma transportada a um plano estético - e a configuração de um sujeito poético em sintonia com uma dispersão própria (PAIXÃO, 2005, p. 23-24).

O movimento que surgia precisava inventar uma vida nova e uma literatura nova. A 
ideia do Orfismo era criar uma poesia alucinante, irreverente e também sem compromisso com ideologias de caráter histórico: buscava-se o rompimento com o passado, mesmo com o Simbolismo, um dos movimentos inspiradores. O propósito da revista, nas palavras de Pessoa, era:

Criar uma arte cosmopolita no tempo e no espaço [...] Por isso a verdadeira arte moderna tem que ser maximamente desnacionalizada acumular dentro de si todas as partes do mundo. Só assim será tipicamente moderna. Que a nossa arte seja uma onde a dolência e o misticismo asiático, o primitivismo africano, o cosmopolitismo das Américas, o exotismo ultra da Oceânia e o maquinismo decadente da Europa se fundam, se cruzem, se interseccionem. E, feita esta fusão espontaneamente, resultará uma arte-todas-as-artes, uma inspiração espontaneamente complexa... (PESSOA, 1917, p. 407-408).

A partir disso, pode-se perceber a estética sensacionista na medida em que esta procura não excluir as outras vanguardas. A arte sensacionista engloba, assim como o Orfismo, "todas as partes do mundo", todos os outros "ismos" literários.

Os textos teóricos de Fernando Pessoa acerca do Sensacionismo foram escritos, entre 1914 e 1916. O que seria, então, o Sensacionismo? Pessoa, em um manuscrito datado possivelmente de 1916, estabeleceu os três princípios para a vanguarda portuguesa: “1. Todo objeto é um sensação nossa. 2. Toda a arte é a conversão duma sensação em objeto. 3. Portanto, toda a arte é a conversão duma sensação numa outra sensação" (PESSOA, 1976, p. 426). Em outro manuscrito, mais longo e da mesma data, o poeta discorre sobre os fundamentos do Sensacionismo:

O Sensacionismo difere de todas as atitudes literárias em ser aberto, e não restrito [...] Assim, ao passo que qualquer corrente literária tem, em geral, por típico excluir as outras, o Sensacionismo tem por típico admitir as outras todas [...] O Sensacionismo é assim porque, para o Sensacionista, cada idéia, cada sensação a exprimir tem de ser expressa de uma maneira diferente daquela que exprime outra (PESSOA, 1976, p. 434).

São esses os princípios e os fundamentos que caracterizam o Sensacionismo como filosofia artística, isto é, são os aspectos que ele sustenta na medida em que aceita todos os sistemas e escolas de arte, extraindo de cada um a beleza e a originalidade que lhe são peculiares. Ressaltando que o Sensacionismo não somente é tido como uma filosofia de arte, visto que "além de sua atitude de aceitação universal do que é belo, apresenta uma originalidade sua própria” (PESSOA, 1976, p. 445).

Para Fernando Pessoa, “o Sensacionismo afirma, primeiro, o princípio da 
primordialidade da sensação - que a sensação é a única realidade para nós" (PESSOA, 1976, p. 449). Tendo isso em vista, o Sensacionismo comporta as duas espécies de sensações que podemos ter: as sensações aparentemente vindas do exterior e as sensações aparentemente vindas do interior. Pesssoa constata que há, ainda, uma terceira ordem de sensações resultantes do trabalho mental - as sensações do abstrato.

Com o intuito de definir o Sensacionismo, Cabral Martins, na coletânea Poesias de Álvaro de Campos (1986), faz uso das palavras do poeta português: "Diz Pessoa: 'Por sensação entende Caeiro a sensação das coisas tal como são, sem acrescentar quaisquer elementos do pensamento pessoal, convenção, sentimento ou qualquer outro lugar da alma”" (MARTINS, 1986, p. 24). Deste modo, constituiu-se o Sensacionismo na sua vertente objetiva. Porém, Álvaro de Campos está relacionado à outra vertente da estética: a objetiva, pois sente as coisas, de todas as maneiras. Ora, a sensação pode surgir de uma imagem, ou ainda constituir-se por meio de uma sensação de outra sensação, seja ela recordada, lida ou mesmo temida. Diante do exposto, analisaremos os poemas "Afinal, a melhor maneira de viajar é sentir", de Álvaro de Campos, e "Rodopio", de Mário de SáCarneiro.

O poema "Afinal, a melhor maneira de viajar é sentir", de Álvaro de Campos, apresenta características sensacionistas no que tange à descrição das sensações, seja ao doutrinar sobre o sentir ou seja por expressar a "alucinação extraordinariamente nítida das sensações":

Afinal, a melhor maneira de viajar é sentir.

Sentir tudo de todas as maneiras.

Sentir tudo excessivamente,

Porque todas as coisas são, em verdade, excessivas

E toda a realidade é um excesso, uma violência,

Uma alucinação extraordinariamente nítida

Que vivemos todos em comum com a fúria das almas,

O centro para onde tendem as estranhas forças centrífugas

Que são as psiques humanas no seu acordo de sentido (PESSOA, 1992, p. 84).

É possível perceber que o eu-lírico pretende "sentir tudo de todas as maneiras" almejando o excesso:

Quanto mais eu sinta, quanto mais eu sinta como várias pessoas, Quanto mais personalidades eu tiver,

Quanto mais intensamente, estridentemente as tiver,

Quanto mais simultaneamente sentir com todas elas, [...] (PESSOA, 1992, p. 84). 
Ao tratar de Orpheu e do Sensacionismo, Fernando Pessoa afirma que essa nova arte, "em vez de ter regras como as artes do passado, passa a ter só uma regra - ser a síntese de tudo [...] Que cada um de nós multiplique a sua personalidade por todas as outras personalidades" (PESSOA, 1976, p. 428). Assim, ao exprimir suas ânsias pelo sentir, Álvaro de Campos expõe a necessidade de obter as sensações através de "várias pessoas", e, para isso, quanto mais personalidades ele possa ter, mais intenso e mais completo ele seria. Verifica-se também a necessidade de Fernando Pessoa da pluripersonalização (“Quanto mais personalidades eu tiver”).

Em “Afinal, a melhor maneira de viajar é sentir”, Álvaro de Campos distancia-se do tema das máquinas, pelo qual é tão versado, mas não deixa de nutrir a necessidade de sentir intensamente. $\mathrm{O}$ eu-lírico fala das sensações fortes, da fúria da natureza, da Vida, do Universo e de Deus. Elucida ainda a Matéria e o Espírito como "[...] apenas nomes confusos / Dados à grande sombra que ensopa o Exterior em sonho" (PESSOA, 1992, p. $85)$.

O eu-lírico intenciona sentir a Natureza excessivamente. Nos seguintes versos é notável a afinidade da Natureza com a visão materna. Dessa forma, a relação entre a Terra e os elementos da natureza se faz harmoniosa:

$[\ldots]$

Sursum corda! Ó Terra, jardim suspenso, berço

Que embala a Alma dispersa da humanidade sucessiva!

Mãe verde e florida todos os anos recente,

Todos os anos vernal, estival, outonal, hiemal,

Todos os anos celebrando às mancheias as festas de Adónis

$[\ldots]$

Mãe carinhosa e unânime dos ventos, dos mares, dos prados,

Vertiginosa mãe dos vendavais e ciclones,

Mãe caprichosa que faz vegetar e secar [...] (PESSOA, 1992, p. 85; grifo nosso).

No entanto, essa mesma Natureza, arquétipo de Mãe, por sentir excessivamente, contém caráter traiçoeiro: perturba a si mesma, confunde o eu-lírico e pode ser devastadora ao romper o equilíbrio. A Natureza que celebra com Adónis ${ }^{5}$ as estações do ano é a

\footnotetext{
${ }^{5} \mathrm{O}$ excerto demonstra essa harmonia com a natureza ao falar de Adónis, filho do rei Cinírias de Chipre e sua filha Mirra. Adónis despertou o amor de duas deusas Perséfone e Afrodite e foi disputado por elas, Zeus intervindo e definindo que ele deveria passar um terço do ano com cada uma das deusas. Mais tarde, Adónis passou a representar o mito da vegetação, indicando a semente que passa quatro meses germinando na terra.
} 
bacante do movimento e da mudança: “[...] perturba as próprias estações e confunde/ Num beijo imaterial os sóis e as chuvas e os ventos!” (PESSOA, 1992, p. 85; grifo nosso).

O eu-lírico trata de um "Universo Excessivo" ao definir-se como "[...] um monte confuso de forças cheias de infinito/Tendendo em todas as direcções para todos os lados do espaço (PESSOA, 1992, p. 86). "Estrelas", "sóis de outros sistemas" e "astros remotos" constituem a essência desse ser sensível a tudo.

Reflete ainda sobre Deus e a Vida:

$[\cdots]$

A Vida, essa coisa enorme, é que prende tudo e tudo une

E faz com que todas as forças que raivam dentro de mim

Não passem de mim, não quebrem meu ser, não partam meu corpo,

Não me arremessem, como uma bomba de Espírito que estoira $[\ldots]$

Sou uma chama ascendendo, mas ascendo para baixo e para cima, Ascendo para todos os lados ao mesmo tempo, sou um globo

De chamas explosivas buscando Deus e queimando

A crosta dos meus sentidos, o muro da minha lógica, A minha inteligência limitadora e gelada.

$[\ldots]$

Meu corpo é um centro dum volante estupendo e infinito

Em marcha sempre vertiginosamente em torno de si, Cruzando-se em todas as direcções com outros volantes, Que se entrepenetram e misturam, porque isto não é no espaço Mas não sei onde espacial de uma outra maneira-Deus (PESSOA, 1992, p. 86-87; grifo nosso).

A busca incessante em obter todas as sensações leva o eu-lírico a transportar-se ao plano da Vida, seja ela no Universo ou à maneira de Deus, tendo então que afastar-se da própria lógica. Por isso, sente tudo infinitamente “em todas as direções”. E mesmo que seja "obrigado ao equilíbrio" não há limitações para o seu sentir, o que acaba fazendo com que sua alma transborde:

Sou um formidável dinamismo obrigado ao equilíbrio

De estar dentro do meu corpo, de não transbordar da minh'alma.

Ruge, estoira, vence, quebra, estrondeia, sacode, Freme, treme, espuma, venta, viola, explode, Perde-te, transcende-te, circunda-te, vive-te, rompe e foge, Se com todo o meu corpo todo o universo e a vida, Arde com todo o meu ser todos os lumes e luzes, Risca com toda a minha alma todos os relâmpagos e fogos, Sobrevive-me em minha vida em todas as direcções! (PESSOA, 1992, p. 88). 
Em concordância com o que foi ilustrado do poema de Álvaro de Campos, podemos elucidar também a estética sensacionista por meio do poema "Rodopio", de Mário de Sá-Carneiro.

Ao tomarmos para análise o poema "Rodopio" (1913), contido no livro Dispersão (1914), pretende-se comprovar as marcas do Sensacionismo, as quais trazem um novo vigor à literatura urbana, dramática, finissecular, produzida pelos dois poetas apresentados. O livro de poesias Dispersão (1914) apresenta poemas que abordam questionamentos acerca da existência e da identidade do eu-lírico, que se vê disperso em si mesmo. Fernando Paixão supõe que a poética carneiriana aspira a uma nova abordagem e afirma que o poeta português "investiu na criação de um conturbado universo de cor, movimento, luz e som" (PAIXÃO, 2005, p. 19). O drama labiríntico do poema homônimo também apresenta um exacerbado sentir, porém contido no "eu mesmo, o outro", não deixando de traduzir certo sensacionismo embutido num foco mais interiorizado.

Ao contrário do poema de Álvaro de Campos, que não se prende a nenhuma forma fixa e tem versos brancos e livres, o poema "Rodopio", de Mário de Sá-Carneiro, é escrito em 11 estrofes de 5 versos cada, sendo estes escandidos em redondilha maior 7 sílabas poéticas). As rimas com um ritmo contínuo (ABBBA) sugerem um círculo ou um rodopio, como diz o nome do poema.

O eu-lírico afirma existir dentro de si diversas maravilhas "que não se podem sonhar". No primeiro verso, ao expressar "Volteiam dentro de mim", o eu-lírico passa então a descrever a mescla de sensações internas.

Através da construção rítmica do poema, temos a sensação de estar "rodopiando" junto ao turbilhão de "acontecimentos" que afetam o eu-lírico: "Ascendem hélices, rastros..."; "Ruem-se braços de cruz"; "Precipitam-se estilhaços"; "Enclavinham-se delírios", dentre outros. A junção de paradoxos ("Há missas e bacanais”), efeitos ("Silvam madeixas ondeantes”) e rememorações ("Há pobres coisas guardadas - / Um lenço, fitas, dedais...") aguçam os cinco sentidos do eu-lírico, arrebatando um emaranhado de coisas e sensações que o perturbam e que, ao mesmo tempo, o fascinam.

O uso de palavras hiperbólicas para a descrição das sensações forma imagens: que podem ser lembranças de momentos vividos pelo eu-lírico ("Há velhas cartas rasgadas,/ Há pobres coisas guardadas - / Um lenço, fitas, dedais...”) ou mesmo ilusões e desejos de vivenciar todas as situações expressas no decorrer do poema ("Tantas, tantas maravilhas/ Que se não podem sonhar!...”). 
Tudo que se passa no poema, todos os sentimentos, sensações, pesadelos, enfim, tudo o que o eu-lírico qualifica como "maravilhas", ocorrem dentro do seu ser, "rodopiando" devagar, deixando o poeta num estado de devaneio, repleto de delírios, refletindo profundamente sobre seus desejos.

Face ao exposto, os poemas "Afinal, a melhor maneira de viajar é sentir" e "Rodopio" constituem-se como poemas síntese dessa estética Sensacionista criada por Fernando Pessoa e Mário de Sá-Carneiro. Os poemas trazem as principais noções da estética que se mescla às suas vanguardas vizinhas.

\section{REFERÊNCIAS BIBLIOGRÁFICAS}

FIGUEIREDO, Fidelino de. História literária de Portugal. 3. ed. São Paulo: Companhia Editora Nacional, 1966.

MOISÉS, Massaud. A literatura portuguesa. 16. ed. São Paulo: Cultrix, 1980.

MOISÉS, Massaud. Dicionário de termos literários. 14 ed. São Paulo: Cultrix, 2004.

MOISÉS, Massaud. A criação literária: poesia e prosa. Ed. rev. e atual. São Paulo: Cultrix, 2012.

PAIXÃO, Fernando. Narciso em sacrifício: a poética de Sá-Carneiro. São Paulo: Atelier Editorial, 2003.

PESSOA, Fernando. Poesias de Álvaro de Campos. São Paulo: FTD, 1992. (Grandes leituras)

PESSOA, Fernando. Obras em prosa. 2. ed. Rio de Janeiro: Nova Aguilar, 1976.

REIS, Carlos. O conhecimento da literatura: introdução aos estudos literários. Coimbra: Gráfica de Coimbra, 1999.

SÁ-CARNEIRO, Mário de. Rodopio. In: SÁ-CARNEIRO, Mário de. Obra completa: volume único. Introd. e Org. de Alexei Bueno. Rio de Janeiro: Nova Aguilar, 1995.

Artigo recebido em 21 de abril de 2014

Artigo aceito em 02 de maio de 2014 